\title{
Simulation Is Not a Pedagogy
}

\author{
Gwen D. Erlam, Liz Smythe, Valerie Wright-St Clair \\ Department of Health and Environmental Sciences, Auckland University of Technology (AUT), Auckland, New Zealand \\ Email: gerlam@aut.ac.nz
}

How to cite this paper: Erlam, G.D., Smythe, L. and Wright-St Clair, V. (2017) Simulation Is Not a Pedagogy. Open Journal of Nursing, 7, 779-787.

https://doi.org/10.4236/ojn.2017.77059

Received: May 31, 2017

Accepted: July 17, 2017

Published: July 21, 2017

Copyright $\odot 2017$ by authors and Scientific Research Publishing Inc. This work is licensed under the Creative Commons Attribution International License (CC BY 4.0).

http://creativecommons.org/licenses/by/4.0/ (c) (i) Open Access

\begin{abstract}
Simulation as a teaching/learning tool has evolved at an unprecedented pace which some believe has occurred despite a lack of research into pedagogies appropriate to guide this technology-based learning tool. There seems to be some confusion as to what simulation actually is. Some have called simulation a pedagogy, which is incorrect. Simulation is not a pedagogy, but an immersive teaching/learning platform which is a representation of a functioning system or process. Simulation has been used in undergraduate nursing education in a focused manner for nearly 20 years. Its effectiveness in improving clinical reasoning and critical thinking is not certain if overall instructional design principles do not reflect suitable philosophical paradigms. Simulation as a teaching/learning platform is maximized when instructional design includes the inspiration of behaviorism, cognitivism, and constructivism. Behaviorist design principles include rote learning, repetition, modular learning, stimulus-response, and conditioning. Cognitivist design principles include observational techniques, bootstrapping, and equilibration in the form of assimilation and accommodation. Constructivist design principles include new habit formation through experience and interaction with a "mature social medium" in the form of a simulation facilitator. All of these philosophical underpinnings have the potential to maximize simulation when used as underpinnings in the overall design.
\end{abstract}

\section{Keywords}

Simulation, Undergraduate Nursing Education, Behaviorist, Cognitivist, Constructivist

\section{Introduction}

There has been some confusion as to the definition and potential uses of simulation in the training of undergraduate nurses. Upon researching simulation extensively, it has become apparent that there is some confusion around the definition of simulation. Some educators believed simulation to be a pedagogy [1]. 
Simulation is not a pedagogy, but an immersive teaching/learning platform which is a representation of a functioning system or process [2]. The aim of this article is to "unpick" some of these language traps in order to better understand how a sound pedagogical approach that includes the use of simulation can maximize learning for undergraduate nurses.

\section{What Is Pedagogy?}

Pedagogy is rarely made explicit in curricula, and is often assumed or taken for granted. Pedagogy deals with the theory and practice of teaching. The Merriam Webster online dictionary [3] defines pedagogy as the art, science, or profession of teaching. A comprehensive use of pedagogy includes considerations around the nature of knowledge; what is taught; how it is taught; and how learning occurs [4]. It is an educator's pedagogical knowledge which most profoundly influences the teaching/learning environments he or she creates [5]. Designing effective simulation involves a comprehensive understanding of the pedagogical underpinnings which can enhance simulation as a teaching/learning tool. Simulation is not a pedagogy in itself; but rather a tool or method used to implement various pedagogies [6].

There are at least three philosophical perspectives which underpin sound simulation design: 1) behaviorism [7] [8] [9]; 2) cognitivism [10] [11] [12]; and 3) constructivism [13] [14] [15] [16]. These can be seen in Figure 1.

Each of these theoretical frameworks involves, to some degree, repetitive practice, feedback, personal and group reflection, and a safe learning environment. Cognitivism and constructivism involve movement from dependent to independent learning. All of these theoretical frameworks have contributions to make to a pedagogical approach that includes the use of simulation [6].

\subsection{Behaviorism}

Behaviorism as an educational philosophy is the earliest theoretical underpinning

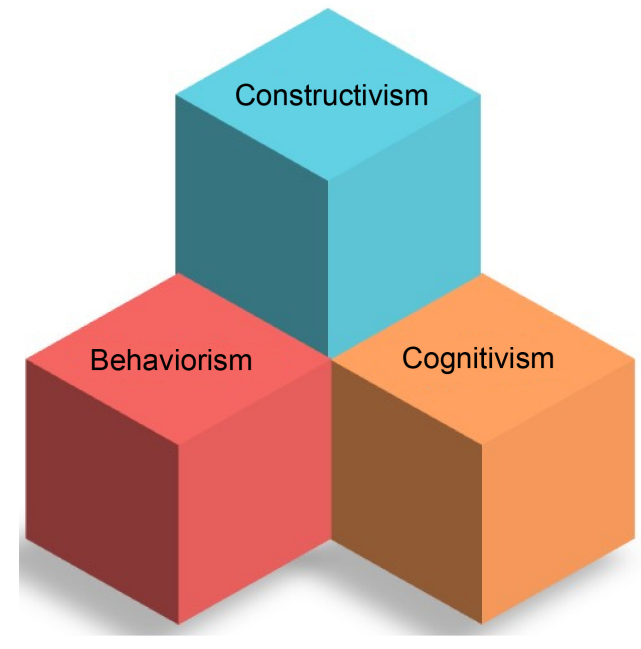

Figure 1. Building blocks of sound simulation design. 
identified in educational research [8] [17] [18]. In behaviorism learning is confirmed by behavioral responses to specific stimuli [17] [19]. John B. Watson (1878-1958) is generally considered to be the founder and champion of modern behaviorism. Watson believed that behavior was the proper material for study, not methods that dealt with the mind [9]. Internal thought processes are not considered as the focus is on external response to stimuli. The human mind is considered a memory bank for knowledge, with the teacher being responsible for transmission of knowledge, and the learner a passive recipient [20]. Behaviorists espouse that environment shapes behavior and that external factors can be manipulated to produce desirable actions [6] [21].

Behaviorist methods employed in simulation include rote learning, repetition of skills, pre-briefing, and modular learning [21]. While basic and often assumed, rote learning forms the foundations of any professional healthcare career by providing students with a body of facts (e.g. lab values, physiology, and clinical protocols) [19] [22]. Application of factual knowledge to clinical problems is the beginning of bridging the theory-practice gap so often noted as an issue in undergraduate nursing education [6].

Conditioning theories of learning, arising from behaviorism, are also helpful in maximizing simulation design [6]. Skinner [7] developed the best-known conditioning theory termed operant conditioning. If a behavior is positively reinforced through conditioning, a response is more likely to occur. Students can therefore be conditioned to respond to certain stimuli (e.g. loss of consciousness, rapid pulse,) with appropriate responses (e.g. BP check) in simulation. Quickened conditioned responses can improve patient outcomes. Thorndike (1874-1949) extended Skinner's work by making deliberate associations between experiences and responses in what was called connectionism [8] [23].

Connectionism espouses that the most fundamental type of learning involves the forming of associations (connections) between sensory experiences (stimuli or events) and neural impulses (responses) that manifest themselves behaviorally [24]. Thorndike [8] proposed the law of exercise, which suggests that practice strengthens the connection between the stimulus and the response, while disuse weakens it. Skill development employing repetition strengthened with the law of exercise can result in modified and improved competence [25] [26] [27].

The positive aspects of behavioral theory include the development of skills in response to certain stimuli, and an assurance that learners will respond in similar ways when in similar circumstances. While this has its place in nursing education, it does involve a mechanistic stimulus-response approach which cannot account for all behavior [28]. Behaviorism is not concerned with creativity or autonomy of learners, nor with their internal mental states [6]. Behaviorism is less concerned with solving the problem and more concerned with how the right outcome can be conditioned and repeated. This lack of focus on judgment, critical thinking, and analysis has become part of the criticism of behaviorism [6] [28]. It could be said that behaviorism has a reductionist approach which limits its usefulness in developing thinking at higher levels required for professional 
practice. This weakness has highlighted a need to seek out other educational philosophies more focused on the student's ability to problem-solve and critically evaluate clinical situations [6]. Therefore, the influence of cognitivist and constructivist philosophies has proved valuable in simulation design.

\subsection{Cognitivism}

While behaviorists believe that learning occurs as a response to stimuli, cognitivism carries the notion that learning involves the reorganization of experiences [6] [29]. Behaviorists stress the role of the environment and the effect on learning, while cognitivists stress what students do with the information. Cognitivists want to know how students attend to, rehearse, transform, code, store, and retrieve information given [24]. The leading, and most influential, cognitive theorist in the West is Piaget [30], while Vygotsky's work [12] is more influential in Eastern Europe [6] [31]. Learning to the cognitivist involves a move away from stimulus-response modes of learning to a focus on students' beliefs and thought processes, perceptions and insights [5] [6] [24].

One of the major challenges to behaviorism came from the studies on observational learning conducted by Albert Bandura [10]. Bandura found that people could learn new actions merely by observing others perform. More importantly, observers did not have to perform the actions at the time of learning. This cognitivist notion impacts simulation design in the area of pre-briefing material and model simulation clips used to showcase professionals caring for clients in deteriorating clinical situations. Students can learn by simply observing model clips [6]. They are able to build this learning into cognitive schema before attending simulation sessions. Piaget's [11] work inspired thoughts on how to maximise the development of such cognitive schema.

According to Piaget [11], equilibration, the drive to produce an optimal state of equilibrium (or adaptation) between cognitive structures and the environment, is the primary motivating force behind cognitive development. To resolve internal conflict in thought, an individual can use one of two component processes of equilibration: assimilation or accommodation. Assimilation refers to fitting external reality into existing cognitive structures. Accommodation refers to changing internal structures to provide consistency with external reality [24]. Both of these processes inspire learning in simulation as students strive to achieve equilibrium.

An example of accommodation occurred when students were shown a model clip of lecturers caring for a croup baby in crisis. The model clip showed the administration of nebulized medication before the intra-muscular injection [6]. Students had previously performed the simulation giving the injection first followed by the nebulizer. Upon noticing the opposite order in the model clip, they amended their own performance to provide consistency with this external reality. They were even able to give rationale for why this change was correct, "The nebulized medication is absorbed more quickly than the injection so should be given first". This accommodation and explanation gave the students added con- 
fidence they were competent to care for such a patient safely [27].

Ironically, one weakness of cognitivism arises from its strength. Whereas schemata can make learning more meaningful, a learner is at a marked disadvantage when relevant schemata or pre-requisite knowledge do not exist [6] [29]. In this instance, the learner may enter into a process called bootstrapping which involves the creation of new representational resources which are more powerful than those present at the outset [32]. In order for bootstrapping to occur, three processes must arise: 1) the facilitator must specify the innate representations that provide the building blocks of the target concepts of interest; 2) the facilitator must describe how the target concepts differ from those innate representations currently available and: 3 ) the facilitator must characterize the learning mechanisms that enable the construction of new concepts out of the prior representations [32]. Facilitator input in the form of situated teaching is essential for bootstrapping to occur [27].

It is the job of the instructional designer to choose tasks which will assist students to retrieve and work with knowledge as they reorganize experiences in cognitive schemata [6]. Cognitive theory underpins simulation in the area of developing clinical reasoning and problem solving [6] [33]. Without consideration of cognitive architectural features, instructional design is likely to be suboptimal [34]. Constructivist philosophy moves simulation design in a different direction.

\subsection{Constructivism}

Constructivist thought draws from a variety of disciplines including education and psychology. John Dewey [14], Jerome Bruner [13], Ernst von Glasersfeld [35], John Mezirow [16], and Malcolm Knowles [15] represent some profound thinkers whose work contributes to contemporary constructivist thought. Constructivist knowledge develops by a process of active construction and reconstruction of theory and practice [6] [36]. Von Glasersfeld [35] postulates that knowledge is the collection of conceptual structures that are adapted or viable within the subject's range of experience.

Constructivism holds that learners have some prior knowledge and experience, and are capable of building their own content in order to solve a particular problem [37] [39]. Constructivism is a learner-centric educational paradigm where the learner constructs meaning in a team-based, collaborative learning environment. The needed knowledge is not delivered by the educator, but constructed in the mind of the learner [38]. The learner moves from a passive stance in behaviorism, to an active participant in the learning process in constructivism [6] [19].

Constructivism impacts simulation design in the area changing outdated habits in favor of more effective ones [14]. Dewey [39] contributed to constructivist thought when he emphasized the construction of meaning in learning environments through experiences and interactions with others. According to Dewey [14], telling students what to do will not embed new ways of thinking/acting 
(i.e. new habits). Learners must be allowed the freedom to consciously search for new ways of responding, while being given the freedom to find their own solutions [6]. These solutions are further refined when students interact with a "matured social medium" [[14] p. 90]. This combination of student search intermingled with facilitator input allows for knowledge construction in a manner which situates the learner firmly in the driver's seat, a concept at the heart of constructivist thought [6] [27].

An example of new habit formation encouraged by the presence of a matured social medium occurred when a student forgot to wear her watch and was forced to view another student's watch. When the other student shifted position, the count was lost. The facilitator pointed out the clock on the wall and the new habit of using the wall clock was formed [6]. The problem was solved and the student commented:

I did not realize there was a clock on the wall, so I could not effectively measure respiratory rate. It was very supportive that [the educator] told me the location of the clock. It was good that the educator was with me (Focus Group, Cycle One).

This kind of facilitation becomes essential for students when they are attempting to form new habits. They appreciate the interaction with a matured social medium in the form of a simulation facilitator, who can give them feedback during and after the simulation in the form of debriefing [6].

One of the challenges posed with constructivism is that learners may inadvertently build knowledge that is inaccurate or not the best "fit" for the problem posed [40]. Some pre-existing ideas may be ad hoc or unstable [41]. If the facilitator is not aware of what a particular student is "thinking", incorrect solutions may result. This problem can be mitigated by training simulation facilitators to monitor and guide student thinking in the debriefing session [6]. This is one reason why debriefing, to ensure refinement of new knowledge, is an essential component when using simulation as a teaching/learning platform [6] [42].

\section{Conclusions}

The past 15 years have born witness to a paradigm shift in the delivery of undergraduate nursing programs from transmission-based delivery models to immersive learning environments involving simulation of practice experiences [6] [43]. Simulation is not a pedagogy, but a teaching/learning platform used to facilitate training for undergraduate nurses [6]. In order to maximize simulation's impact on learning, at least three pedagogical underpinnings must be considered: 1) behaviorism; 2) cognitivism; and 3) constructivism. Simulation design elements which move students progressively through rote memory, to acquiring cognitive schema, and finally capturing learning moments through application of memorized and stored information to clinical practice; are the golden nuggets of simulation design. Simulation facilitators must be trained in the implementation of these pedagogical underpinnings in order to ensure a safe and effective student journey through this immersive learning environment. The final result of 
this process will be students "fit for purpose" and ready to engage with complex clinical environments for which they are destined.

\section{References}

[1] McNeill, J., Parker, R.A., Nadeau, J., Pelayo, L.W. and Cook, J. (2012) Developing Nurse Educator Competency in the Pedagogy of Simulation. Journal of Nursing Education, 51, 685-691. https://doi.org/10.3928/01484834-20121030-01

[2] Simulation Australia (2017) What is Simulation: An Overview of Simulation and Modelling. Retrieved June 15, 2017, from http://www.simulationaustralasia.com/about/what-is-simulation

[3] Pedagogy (2015) Retrieved March 19, 2015 from Merriam-Webster.com website. http://www.merriam-webster.com/dictionary/pedagogy

[4] Horsfall, J., Cleary, M. and Hunt, G.E. (2012) Developing a Pedagogy for Nursing Teaching-Learning. Nurse Education Today, 32, 930-933. https://doi.org/10.1016/j.nedt.2011.10.022

[5] Bradshaw, M.J. (2014) Effective Learning: What Teachers Need to Know. In: Bradshaw, M.J. and Lowenstein, A.J., Eds., Innovative Teaching Strategies. Jones \& Bartlett Learning, Burlington, MA, 3-18.

[6] Erlam, G., Smythe, E. and Wright-St Clair, V. (2015) Improving Pedagogical Practices with Undergraduate Nursing Students in High-Fidelity Simulation: A Thesis Submitted to Auckland University of Technology in Partial Fulfilment of the Requirements for the Degree of Doctor of Health Science, 2015. Auckland University of Technology, Auckland.

[7] Skinner, B.F. (1938) The Behavior of Organisms: An Experimental Analysis. B.F. Skinner Foundation, Cambridge, MA.

[8] Thorndike, E.L. (1913) Education Psychology: Briefer Course. Routledge, New York.

[9] Watson, J.B. (1914) Behavior: An Introduction to Comparative Psychology. Henry Holt \& Company, New York. https://doi.org/10.1037/10868-000

[10] Bandura, A. (1977) Social Learning Theory. General Learning Press, New York.

[11] Piaget, J. (1952) When Thinking Begins. In: The Origins of Intelligence in Children, International Universities Press, New York, 25-36.

https://doi.org/10.1037/11494-000

[12] Vygotsky, L. (1980) Mind in Society: The Development of Higher Psychological Processes. Harvard University Press, Cambridge.

[13] Bruner, J. (1960) The Process of Education. Harvard University Press, Cambridge.

[14] Dewey, J. (1922) Human Nature and Conduct: An Introduction to Social Psychology. Henry Holt, New York.

[15] Knowles, M.S. (1973) The Adult Learner: A Neglected Species. Gulf Publishing Company, Houston.

[16] Mezirow, J. (2000) Learning as Transformation: Critical Perspectives on a Theory in Progress. Jossey Bass, San Francisco.

[17] Skinner, B.F. (1985) Cognitive Science and Behaviourism. British Journal of Psychology, 76, 291-301. https://doi.org/10.1111/j.2044-8295.1985.tb01953.x

[18] Watson, J.B. (1925) Behaviorism. W.W. Norton \& Company, Inc., New York.

[19] Passmore, G.G. (2014) Concept Mapping: A Meaningful Learning Tool to Promote Conceptual Understanding and Clinical Reasoning. In: Bradshaw, M.J. and Lo- 
wenstein, A.J., Eds., Innovative Teaching Strategies in Nursing and Related Health Professions, Jones \& Bartlett Learning, Boston, 6th Edition, 397-415.

[20] Chen, I. (2009) Behaviorism and Developments in Instructional Design and Technology. In: Rogers, P., Berg, G., Boettcher, J., Howard, C., Justice, L. and Schenk, K., Eds., Encyclopedia of Distance Learning, 2nd Edition, 153-172. https://doi.org/10.4018/978-1-60566-198-8.ch023

[21] Parker, B.C. and Myrick, F. (2009) A Critical Examination of High-Fidelity Human Patient Simulation within the Context of Nursing Pedagogy. Nurse Education Today, 29, 322-329. http://www.nurseeducationtoday.com/

[22] Lewis, D.Y. and Ciak, A.D. (2011) The Impact of a Simulation Lab Experience for Nursing Students. Nursing Education Perspectives, 32, 256-258.

http://www.nln.org/nlnjournal https://doi.org/10.5480/1536-5026-32.4.256

[23] Tolman, E.C. (1936) Connectionism; Wants, Interests, and Attitudes. Character \& Personality, 4, 245-253. https://doi.org/10.1111/j.1467-6494.1936.tb02126.x

[24] Schunk, D.H. (2014) Learning Theories: An Educational Perspective. 6th Edition, Pearson Prentice Hall, Upper Saddle River.

[25] Clapper, T.C. and Kardong-Edgren, S. (2012) Using Deliberate Practice and Simulation to Improve Nursing Skills. Clinical Simulation in Nursing, 8, e109-e113.

[26] Erlam, G., Smythe, L. and Wright, V. (2016) Simulation and Millennials-The Perfect Storm. Open Journal of Nursing, 6, 688-698.

https://doi.org/10.4236/ojn.2016.69071

[27] Erlam, G., Smythe, E. and Wright-St Clair, V. (2016) Six Steps to Coaching Oscar Performances from Under-Graduate Nursing Students in Simulation: An Action Research Study. The Meeting of the SimHealth, Melbourne, 26-29 September 2016.

[28] Haw, M.A. (2006) Learning Theories Applied to Nursing Curriculum Development. In: Keating, S.B., Ed., Curriculum Development and Evaluation in Nursing, Lippincott Williams \& Wilkins, Philadelphia, 49-60.

[29] McLeod, G. (2003) Learning Theory and Instructional Design. Learning Matters, 2, 35-43. http://www.education.state.mn.us/MDE/Welcome/News/LearnMatter/

[30] Piaget, J. (1973) Main Trends in Psychology. George Allen \& Unwin, London.

[31] Jarvis, P., Holford, J. and Griffin, C. (2003) The Theory and Practice of Learning. 2nd Edition, Kogan-Page, London.

[32] Carey, S. (2004) Bootstrapping \& the Origin of Concepts. Daedalus, 133, 59-68. http://www.jstor.org/stable/20027897 https://doi.org/10.1162/001152604772746701

[33] Burke, H. and Mancuso, L. (2012) Social Cognitive Theory, Metacognition, and Simulation Learning in Nursing Education. Journal of Nursing Education, 51, $543-$ 548. https://doi.org/10.3928/01484834-20120820-02

[34] Josephsen, J. (2015) Cognitive Load Theory and Nursing Simulation: An Integrative Review. Clinical Simulation in Nursing, 11, 259-267.

[35] Von Glasersfeld, E. (1989) Cognition, Construction of Knowledge, and Teaching. Synthese, 80, 121-140. https://doi.org/10.1007/BF00869951

[36] Foreman-Peck, L. and Murray, J. (2008) Action Research and Policy. Journal of Philosophy of Education, 42, 145-163. https://doi.org/10.1111/j.1467-9752.2008.00630.x

[37] Piaget, J. (1954) The Construction of Reality in the Child. Basic Books, New York. https://doi.org/10.1037/11168-000 
[38] Boese, T., Cato, M., Gonzalez, L., Jones, A., Kennedy, K., Reese, C., Borum, J.C., et al. (2013) Standards of Best Practice: Simulation Standard V: Facilitator. Clinical Simulation in Nursing, 9, S22-S25.

[39] Dewey, J. (1938) Experience and Education. Educational Forum, 50, 241-252. https://doi.org/10.1080/00131728609335764

[40] Kala, S., Isaramalai, S.-A. and Pohthong, A. (2010) Electronic Learning and Constructivism: A Model for Nursing Education. Nurse Education Today, 30, 61-66.

[41] Sjøberg, S. (2010) Constructivism and Learning. In: Peterso, P., Baker, E. and McGaw, B., Eds., International Encyclopedia of Education, Elsevier, Philadelphia, 485-490.

[42] Crookall, D. (2011) Serious Games, Debriefing, and Simulation/Gaming as a Discipline. Simulation \& Gaming, 41, 898-920. https://doi.org/10.1177/1046878110390784

[43] Bergero, C., Hargreaves, L. and Nichols, A. (2012) Collaborative Healthcare Immersive Learning Dynamic: Transitioning to Simulation-Based Learning. Clinical Nurse Specialist, 26, 42-47. https://doi.org/10.1097/NUR.0b013e31823bfacf

Submit or recommend next manuscript to SCIRP and we will provide best service for you:

Accepting pre-submission inquiries through Email, Facebook, LinkedIn, Twitter, etc. A wide selection of journals (inclusive of 9 subjects, more than 200 journals)

Providing 24-hour high-quality service

User-friendly online submission system

Fair and swift peer-review system

Efficient typesetting and proofreading procedure

Display of the result of downloads and visits, as well as the number of cited articles

Maximum dissemination of your research work

Submit your manuscript at: http://papersubmission.scirp.org/

Or contact ojn@scirp.org 